\title{
Protective Effects of Green Tea Polyphenol Against Renal Injury Through ROS-Mediated JNK-MAPK Pathway in Lead Exposed Rats
}

\author{
Haidong Wang', Deyuan Lí, Zhongze Hư', Siming Zhao ${ }^{3}$, Zhejun Zheng', and Wei Lí ${ }^{1, *}$
}

To investigate the potential therapeutic effects of polyphenols in treating $\mathrm{Pb}$ induced renal dysfunction and intoxication and to explore the detailed underlying mechanisms. Wistar rats were divided into four groups: control groups (CT), $\mathrm{Pb}$ exposure groups ( $\mathrm{Pb}$ ), $\mathrm{Pb}$ plus Polyphenols groups $(P b+P P)$ and Polyphenols groups (PP). Animals were kept for 60 days and sacrificed for tests of urea, serum blood urea nitrogen (BUN) and creatinine. Histological evaluations were then performed. In vitro studies were performed using primary kidney mesangial cells to reveal detailed mechanisms. Cell counting kit-8 (CCK-8) was used to evaluate cell viability. $\mathrm{Pb}$ induced cell apoptosis was measured by flow cytometry. Reactive oxygen species (ROS) generation and scavenging were tested by DCFH-DA. Expression level of tumor necrosis factor- $\alpha$ (TNF- $\alpha$ ), interleukin-1- $\beta$ (IL-1- $\beta$ ) and IL-6 were assayed by ELISA. Western blot and qPCR were used to measure the expression of ERK1/2, JNK1/2 and p38. Polyphenols have obvious protective effects on $\mathrm{Pb}$ induced renal dysfunction and intoxication both in vivo and in vitro. Polyphenols reduced $\mathrm{Pb}$ concentration and accumulation in kidney. Polyphenols also protected kidney mesangial cells from $\mathrm{Pb}$ induced apoptosis. Polyphenols scavenged $\mathrm{Pb}$ induced ROS generation and suppressed ROS-mediated ERK/JNK/p38 pathway. Downstream pro-inflammatory cytokines were inhibited in consistency. Polyphenol is protective in $\mathrm{Pb}$ induced renal intoxication and inflammatory responses. The underlying mechanisms lie on the antioxidant activity and ROS scavenging activity of polyphenols.

\section{INTRODUCTION}

Lead is a heavy, easily malleable and soft metal with symbol

\footnotetext{
${ }^{1}$ College of Food and Biological Engineering, Hubei University of Technology, ${ }^{2}$ Nutrition and Food Research Institute, Wuhan Economic College, ${ }^{3}$ College of Food Science and Technology, Huazhong Agricultural University, Wuhan, PR China

*Correspondence: yeleiliwei2015@163.com

Received 15 June, 2015; revised 25 January, 2016; accepted 1 February, 2016; published online 26 May, 2016
}

Keywords: lead, oxidative stress, polyphenols, ROS, renal inflammation
$\mathrm{Pb}$ in the carbon group. The consumption of $\mathrm{Pb}$ in industry is still huge which make it one of the most commonly seen environmental hazardous material. Exposure to $\mathrm{Pb}$ may occur through contacting contaminated water and polluted air like emission of lead-containing gasoline. $\mathrm{Pb}$ has multiple targets in various organs in human bodies which may cause different health issues. It has been reported that $\mathrm{Pb}$ induces apoptosis in rats erythrocytes (Mandal et al., 2012) and induces renal injury (Navarro-Moreno et al., 2009). Nervous system, cardiovascular system, and digestive system are also proved to be sensitive and can be injured by $\mathrm{Pb}$ exposure and accumulation (Dai et al. 2009; Luo et al., 2012; Poreba et al., 2012). Kidney is one of the main targets of $\mathrm{Pb}$; however, the precise injury mechanisms remain unclear making it worthy to perform more studies on $\mathrm{Pb}$ induced renal toxicity and to discover potential treatment.

The toxic effects of $\mathrm{Pb}$ on renal function are multifaceted. Increased inflammatory response is one of the key mechanisms in $\mathrm{Pb}$ induced renal toxicity. Studies in both human and animals revealed that proinflammatory molecules including tumor necrosis factor- $\alpha$ (TNF- $\alpha$ ), interleukin-1- $\beta$ (IL-1- $\beta$ ), and IL-6 were significantly over expressed under lead exposure (Liu et al., 2000; Mishra et al., 2003; Struzynska et al., 2007). Another crucial mechanism of $\mathrm{Pb}$ induced renal toxicity is the DNA damage and cell apoptosis mediated by oxidative stress. Inhibition of antioxidant enzyme expression, over generation of ROS, and Caspase-3 activated cell apoptosis were also proved associated with lead toxicity.

Polyphenols are a class of chemical compounds with a various amounts of phenol units. Characterized by different phenol units, polyphenols can be divided into different classes according to specific biological properties (Zou and Xie, 2013). Polyphenols are widely spread in our daily dietary and represents the most abundant antioxidants intake (Bohn, 2014; Ohara and Ohyama, 2014). Polyphenols can be extracted from a variety of natural products like grape skin, seeds, tree bark, and olive pulp, which are already used for dietary supplements and cosmetics (Cardona et al., 2013; Joven et al., 2014). Polyphenols have many potential health benefits in human health. It has been proved that polyphenols have remarkable antioxidant and anti-inflammatory effects that are beneficial in cardiovascular system, digestive system, and tumor prevention (Cardona et al., 2013; Chu, 2014; Khurana et al., 2013; Qiao et al., 2014; Yang et al., 2014). Polyphenols were also reported detoxicate and removal-orientated in heavy metal intoxication (Copello et al., 2013). To our knowledge, no report has been made on the 
Table 1. Primer sequences for $\mathrm{qPCR}$

\begin{tabular}{|c|c|c|c|}
\hline Primers & Forward & Reverse & $\operatorname{Tm}\left({ }^{\circ} \mathrm{C}\right)$ \\
\hline Erk1 & 5'-GCTTACCAGGCAACAT-3' & 5'-CTGGCACCAGAAACGA-3' & 59 \\
\hline Erk2 & 5'-ACCCGAAGCGGACATT-3' & 5'-GGCATCTCCCTGAACG-3' & 61 \\
\hline JNK1 & 5'AGATGGAGATTTCTGATGGTCCTC-3' & 5'-CTTGCTTAGTTTCTTGTCTGGTGG-3' & 60 \\
\hline JNK2 & 5'-TACCCACCTCAGACAACAGCACC-3' & 5'-ATCCCCAATCAGAAAACCAGCAC-3' & 60 \\
\hline P38 & 5'-AGATGG ACCTCGGGAG-3' & 5'-ATCAAT CACGCACGATTT-3' & 58 \\
\hline$\beta$-actin & 5'-TCССТGTATGCСTCTG-3' & 5'-ATGTCACGCACGATTT-3' & 61 \\
\hline
\end{tabular}

protective effects of polyphenols in $\mathrm{Pb}$ induced renal toxicity.

The aim of our study was to investigate the potential protective effects of polyphenols in $\mathrm{Pb}$ induced renal toxicity. Taking consideration of the anti-inflammatory, antioxidant, and ROS scavenging activity of polyphenols, we hypothesized that polyphenols may also be protective in $\mathrm{Pb}$ induced renal intoxication.

\section{MATERIALS AND METHODS}

\section{Chemicals and reagents}

All chemicals and reagents were obtained from Sigma Aldrich (USA) if no indications were given. All antibodies were purchase from Santa Cruz if no indications were given. RPMI 1640 medium and fetal bovine serum (FBS) were purchased from Gibco (Life Technologies, USA). Penicillin-streptomycin solution was obtained from Hyclone (Thermo Scientific, USA). 2', 7'-dichlorofluorescein diacetate (DCFH-DA) was obtained from Molecular Probes (USA). Polyphenols were obtained from Sigma-Aldrich (USA).

\section{Cell culture}

Primary kidney mesangial cells were isolated from Wistar rat kidney tissue. Cells were then cultured in RPMI 1640 medium with $10 \%$ fetal bovine serum (FBS) and $1 \%$ penicillin and streptomycin. Isolated primary cells were incubated at $37^{\circ} \mathrm{C}$ with $5 \%$ $\mathrm{CO}_{2}$ and $95 \%$ humidity. Medium was replaced twice a week in all experiments.

\section{Animals}

The 8 week-old male Wistar rats were purchased from Shanghai Experimental Animal Center (China). Animals were kept under thermostat conditions at about $24^{\circ} \mathrm{C}$ with $55 \%$ humidity with free access to food and clean water. Light was provided 12 $\mathrm{h}$ per day. Animals were randomly divided into six groups (5 rats in each).

(1) Control group, rats were received lead-free redistilled water and daily given physiological saline $(0.9 \% \mathrm{NaCl})$ orally during the whole course of the experiment; (2) $\mathrm{Pb}$ only treated group, rats received an aqueous solution of lead acetate $\left(\mathrm{Pb}\left(\mathrm{CH}_{3} \mathrm{COOH}\right)_{2}\right)($ Sigma-Aldrich, USA) at a concentration of $500 \mathrm{mg} \mathrm{Pb} / \mathrm{L}$ of drinking water; (3) Pb+PP (20 mg/kg) treated group, rats received an aqueous solution of lead acetate (500 $\mathrm{mg} \mathrm{Pb} / \mathrm{L}$ ) and received a daily oral gavage administration of $\mathrm{PP}$ at dose of $20 \mathrm{mg} / \mathrm{kg} / \mathrm{body}$ weight; (4) Pb+PP (50 mg/kg) treated group, rats received an aqueous solution of lead acetate (500 $\mathrm{mg} \mathrm{Pb} / \mathrm{L}$ ) and received a daily oral gavage administration of $\mathrm{PP}$ at dose of $50 \mathrm{mg} / \mathrm{kg} / \mathrm{body}$ weight; (5) PP only treated group, rats received a daily oral gavage administration of $\mathrm{PP}$ at dose of $50 \mathrm{mg} / \mathrm{kg} / \mathrm{body}$ weight. The choice of $\mathrm{Pb}$ and PP dose is based on previous findings of Liu et al. (2012). The experiment lasted for 60 days.

\section{CCK-8 cell proliferation and viability assay}

Primary kidney mesangial cells were seeded $\left(2 \times 10^{3}\right.$ per well) into 96-well plates and were cultured overnight. Culture medium was removed the next day and fresh medium was added together with $\mathrm{Pb}$ or PP consistent with the animal study. Cell proliferation and viability were evaluated on day 1,3 and 5 by Cell Counting Kit-8 (CCK8, Dojindo, Japan) reagent according to the manufacturers' instructions. The absorbency of cells was measured using a 96-well plate reader at $450 \mathrm{~nm}$ (SpectraMax 190).

\section{Flow cytometry and cell apoptosis assay} Apoptosis rate of Primary kidney mesangial cells was detected by Flow cytometry(FCM) with Annexin V-FITC Apoptosis Detection Kit (KeyGEN) following to the manufacturer's instructions. The apoptosis rate was assayed by using FACSCalibur Flow Cytometry (USA) at $488 \mathrm{~nm}$.

Reactive oxygen species (ROS) assay

Primary kidney mesangial cells $\left(5 \times 10^{3}\right.$ cells/well in 96 well plates) were cultured in RPMI 1640 medium (10\% FBS, 1\% antibiotics) for $24 \mathrm{~h}$ and each well was replaced with RPMI 1640 medium (10\% FBS, 1\% antibiotics). Intracellular ROS level was measured by 2', 7'-dichlorofluorescein diacetate (DCFH), which can be oxidized into fluorescent DCF. After fixing, the cells were washed in $1 \times$ PBS and then incubated in the dark for 30 min with $10 \mu \mathrm{M}$ DCFH-DA. Images were taken using the fluorescence of DCF by fluorescence microscopy (Olympus).

Enzyme-linked immunosorbent assay (ELISA)

Levels of murine TNF- $\alpha$, IL-1- $\beta$ and IL- 6 in culture supernatants were assayed by ELISA according to the manufacturers' instructions (R\&D Systems). OD values were measured in an ELISA plate reader at a wavelength of $450 \mathrm{~nm}$.

\section{$q P C R$}

Total RNA was isolated using Trizol reagent (Life Technologies). Reverse transcriptase and oligo'dT primer were used to prepare cDNA from $1 \mu \mathrm{g}$ of RNA according the manufacturer's instructions (Takara, Japan). Two microlitres of each cDNA was then used for PCR amplification using primers for Erk1, Erk2, JNK1, JNK2, p38. The detailed information of primers was shown in Table 1.

\section{Western blot}

Cells were lysed in prepared buffer containing $10 \mathrm{mM}$ Tris, $\mathrm{pH}$ 7.2, $150 \mathrm{mM} \mathrm{NaCl}, 5 \mathrm{mM}$ EDTA, $0.1 \%$ SDS, $0.5 \%$ Triton X-100, and $1 \%$ deoxycholic acid. For Western blots, $30 \mu \mathrm{g}$ of protein 
A

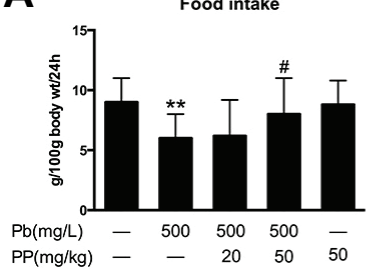

B

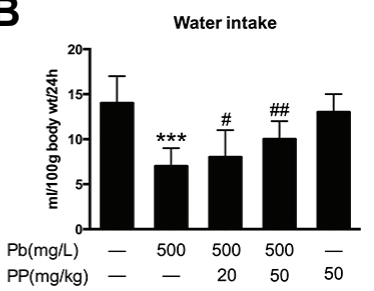

Fig. 1. Food and water intake altered by $\mathrm{Pb}$ treatments. (A) Food intake alteration with treatments of $\mathrm{Pb}$ or $\mathrm{PP}$. (B) Water intake alteration with treatments of $\mathrm{Pb}$ or $\mathrm{PP}$. Data in the figures represent average $\pm S D$. $(n=3)$ * represents comparison with control group and \# represents comparison with $\mathrm{Pb}$ group. ${ }^{*} p<0.05$, ${ }^{* *} p<0.01$, ${ }^{\star \star *} p<0.001, \# p<0.05, \# \# p<0.01, \# \# \# p<0.001$ based on one way ANOVA.

samples were subjected to SDS-PAGE followed by transfer onto PVDF membranes. After blocking in 5\% BSA in PBS, membranes were incubated with antibodies against Erk1, Erk2, JNK1, JNK2, p38, and $\beta$-actin overnight at $4^{\circ} \mathrm{C}$ followed by $1 \mathrm{~h}$ incubation with secondary antibody. Blots against $\beta$-actin served as loading control.

\section{Statistical analysis}

All data were analyzed by Statistical Product and Service Solutions (SPSS, ver. 13.0) software and the results were showed by mean \pm SD. Student's t-test and two-way analysis of variance (ANOVA) were used to assess statistical significance, with $p \leq 0.05$ being regarded as significant.

\section{RESULTS}

\section{Food and water intake altered by Pb treatments}

Food and water intake were evaluated respectively in the four groups (Fig. 1). The results showed that both food and water intake were significantly decreased in $\mathrm{Pb}$ group and $\mathrm{Pb}+\mathrm{PP}$ group $(p<0.05)$. Food and water intake showed no difference between the CT group and PP group. We concluded that $\mathrm{Pb}$ treatment with or without polyphenols led to decreased feeding and drinking in rats (Fig. 1B).

\section{Polyphenols rescued Pb-induced body and kidney weight alterations}

To investigate the effects of $\mathrm{Pb}$ and polyphenols treatments on body and kidney weight change. Body weights were measured consecutively in these two months (60 days). Kidney weights were evaluated after sacrifice of the animals. The results showed that body weight was significantly decreased in the $\mathrm{Pb}$ group compared to the control group $(p<0.01)$ at week 8 (Fig. $2 \mathrm{~A})$. Kidney weight in the $\mathrm{Pb}$ group on the contrary was increased by $12.1 \%$ compared to the CT group $(p<0.01)$. As expected, polyphenols treatments protected the body weight decrease caused by $\mathrm{Pb}$. $\mathrm{Pb}+\mathrm{PP}(50 \mathrm{mg} / \mathrm{kg})$ group showed no significant change in body weight compared to the control group ( $p<0.05$ ) (Fig. 2B). Measurements of $\mathrm{Pb}$ concentration in the kidney tissue also showed that polyphenols decreased $\mathrm{Pb}$ accumulations in the kidney (Fig. 2C).

\section{Polyphenols protected Pb-induced renal dysfunction and tubular injury}

Serum urea and creatinine were tested to evaluate the renal function of rats in each group. Serum urea and creatinine were increased remarkably in the $\mathrm{Pb}$ group compared to the CT group $(p<0.001)$ indicating the clear dysfunction caused by $\mathrm{Pb}$ exposure. In the $\mathrm{Pb}+\mathrm{PP}$ group, the level of the two markers was decreased significantly compare to the $\mathrm{Pb}$ group $(p<0.01)$ (Figs. 3B and $3 \mathrm{C}$ ).To study the effects of $\mathrm{Pb}$ and polyphenols on tubular cell toxicity, H\&E stain was performed to measure tubular injury condition (Fig. 3C). The results indicated that the $\mathrm{Pb}$ group had the severest damaged tubular tissue structure and smallest cell number. The injury was partially rescued when polyphenols was induced in the $\mathrm{Pb}+\mathrm{PP}$ group (Fig. 3A).

\section{Polyphenols reduced $\mathrm{Pb}$-induced cell viability inhibition in vitro \\ In vitro studies were performed to better understand the effects and underlying mechanisms of $\mathrm{Pb}$ toxicity. CCK-8 was used to evaluate the effects of $\mathrm{Pb}$ on cell viability and proliferation. Pri- mary cells were cultured in $\mathrm{Pb}$-contained media with or without treatments of polyphenols. Cell viability and proliferation were assayed by CCK- 8 at $24 \mathrm{~h}$ and $48 \mathrm{~h}$. The rescue effects of polyphenols on $\mathrm{Pb}$-induced cell viability inhibition appeared when the concentration reached to $50 \mathrm{ug} / \mathrm{ml}$ (Fig. 4A). Total cell number was also increased when treated with polyphenols of 2 $\mathrm{ug} / \mathrm{ml}$ compared to the $\mathrm{Pb}$ groups (Fig. 4B).}

\section{Polyphenols inhibited Pb-induced cell apoptosis rate}

We further investigated the effects of $\mathrm{Pb}$ on cell apoptosis of the primary mesangial cells and the potential protective effects of polyphenols. Cells were incubated for $24 \mathrm{~h}$ and $48 \mathrm{~h}, \mathrm{FCM}$ was then performed to evaluate the early and late cell apoptosis rate (Figs. 5A and $5 \mathrm{~B}$ ). The results showed that both early and late apoptosis rate were increased by $\mathrm{Pb}$ treatment; however, the increase was partially attenuated with PP treatments. On the molecular level, qPCR was performed to screen important apoptosis related genes (Figs. 5C-5E). The results indicated that Caspase-3, Bax and $\mathrm{Bcl}-2$ were significantly
A

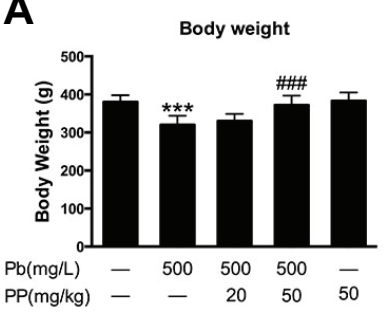

B

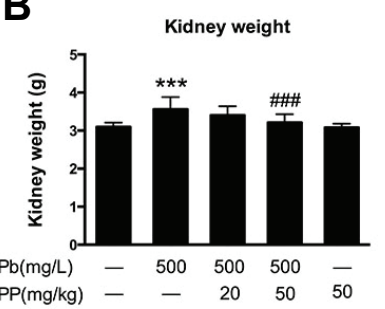

C

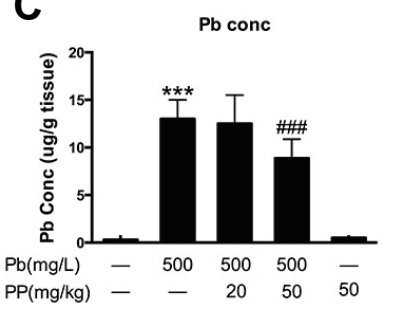

Fig. 2. Polyphenols rescued $\mathrm{Pb}$ induced body and kidney weight alterations. (A) Body weight alteration with treatments of $\mathrm{Pb}$ or $\mathrm{PP}$. (B) Kidney weight alteration with treatments of $\mathrm{Pb}$ or PP. (C) Kidney $\mathrm{Pb}$ concentration alteration with treatments of $\mathrm{Pb}$ or PP. Data in the figures represent average $\pm S D$. $(n=5)$ * represents comparison with control

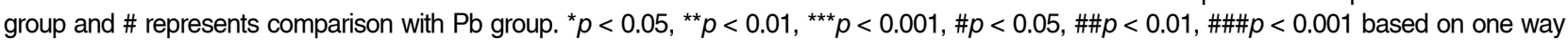
ANOVA. 

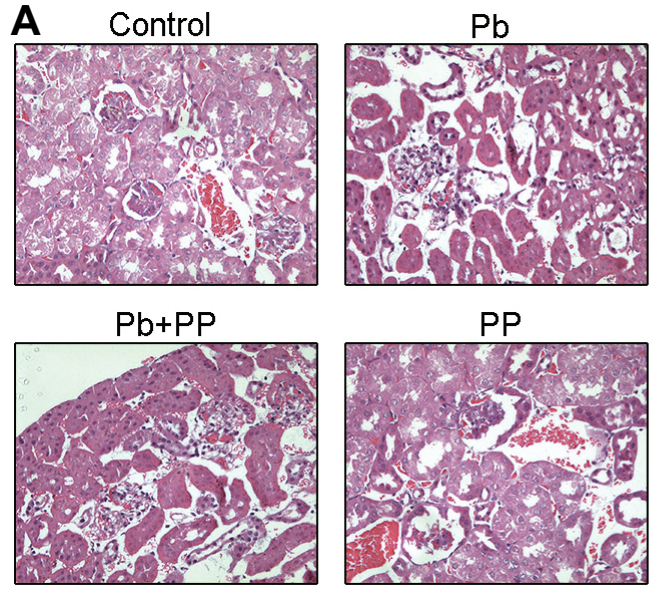

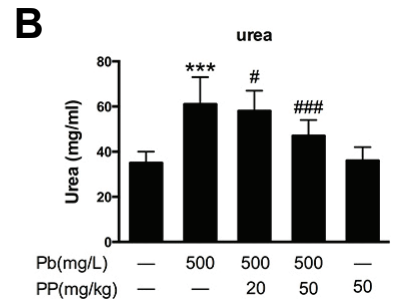

C

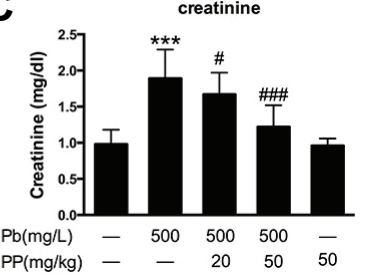

Fig. 3. Polyphenols protected $\mathrm{Pb}$-induced renal dysfunction and tubular injury. (A) Representative $\mathrm{HE}$ stain images of rats kidney treated with $\mathrm{Pb}, \mathrm{PP}$ and $\mathrm{Pb}+\mathrm{PP}$. (B) Blood test of urea concentration. (C) Blood test of creatinine concentration. Data in the figures represent average \pm $\mathrm{SD} .(\mathrm{n}=3)$ * represents comparison with control group and \# represents comparison with $\mathrm{Pb}$ group. ${ }^{*} p<0.05,{ }^{\star \star} p<0.01,{ }^{\star \star *} p<0.001, \# p<$ $0.05, \# \# p<0.01, \# \# \# p<0.001$ based on one way ANOVA.
A

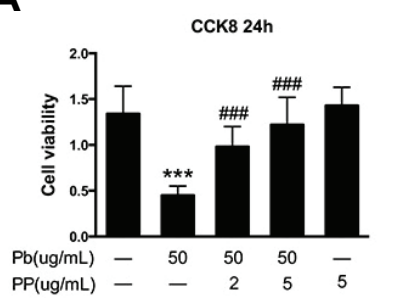

B

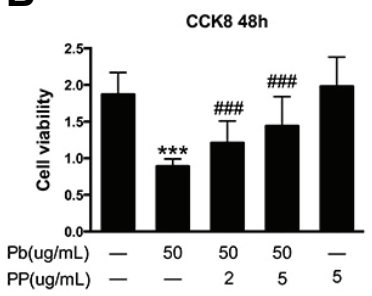

Fig. 4. Polyphenols reduced $\mathrm{Pb}$-induced cell viability inhibition in vitro. (A) Cell viability test via CCK-8 assay at $24 \mathrm{~h}$. (B) Cell viability test via CCK-8 assay at $48 \mathrm{~h}$. Data in the figures represent average \pm SD. (n $=3){ }^{*}$ represents comparison with control group and \# represents comparison with $\mathrm{Pb}$ group. ${ }^{*} p<0.05,{ }^{* \star} p<0.01,{ }^{\star \star *} p<0.001, \# p<$ $0.05, \# \# p<0.01, \# \# \# p<0.001$ based on one way ANOVA.

overexpressed with $\mathrm{Pb}$ treatment, polyphenols treatments partially down regulated their expression.

Polyphenols scavenged ROS production induced by $\mathrm{Pb}$ Since the antioxidant effects of polyphenols have already been reported in other systems. We assumed that polyphenols might also alleviate the $\mathrm{ROS}$ generation induced by $\mathrm{Pb}$ in renal injury. Intracellular ROS levels were analyzed by DCFH-DA, which is cell permeable and oxidation sensitive inside cells. After 24 h's $\mathrm{Pb}$ incubation with or without polyphenols at different dosages, intracellular ROS generation was tested in primary mesangial cells. The results showed that polyphenols remarkably decreased the intensity of DCF fluorescence within cells in a dose-dependent way (Fig. 6A). Quantitative analysis of DCF fluorescence intensity revealed that the ROS scavenging activity of polyphenols started to appeal when the concentration reached to $5 \mu \mathrm{g} / \mathrm{ml}(p<0.05)$.

\section{Polyphenols suppressed inflammatory cytokines release through JNK-MAPK pathway}

To better understand the relationship between polyphenols treatment and inflammation, we tested the pro-inflammatory cytokines release in primary mesangial cells induced with $\mathrm{Pb}$. TNF- $\alpha$, IL-1- $\beta$ and IL- 6 secretion was assayed by ELISA. The results showed that $\mathrm{Pb}$ treatments significantly increased the expression of these cytokines $(p<0.01)$ while treatment of polyphenols decreased the secretion of TNF- $\alpha$ and IL-1- $\beta$ ( $p<$ 0.05 ). IL-6 secretion also showed significant difference (Figs. 7B, 7D, and 7E). To explore the detailed mechanisms, Western
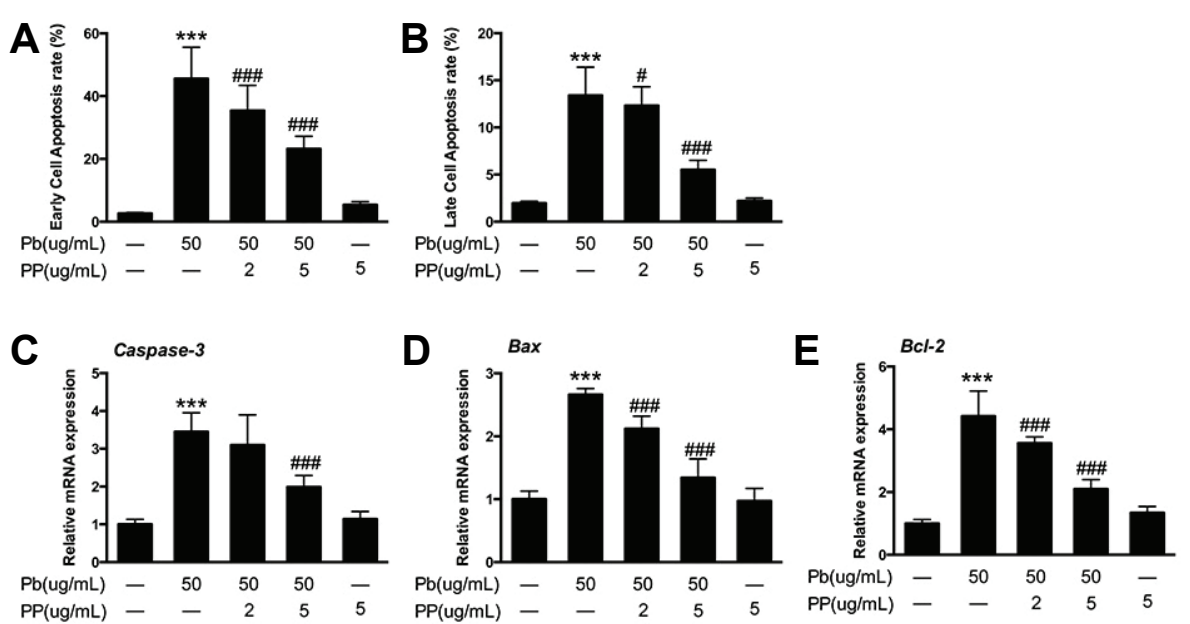

Fig. 5. Polyphenols inhibited $\mathrm{Pb}-$ induced cell apoptosis rate. (A) Early cell apoptosis rate tested by FCM. (B) Late cell apoptosis rate tested by FCM. (C) Relative mRNA expression level of caspase-3. (D) Relative mRNA expression level of Bax. (E) Relative mRNA expression level of $\mathrm{Bcl}$-2. Data in the figures represent average $\pm S D$. $(n=3)$ * represents comparison with control group and \# represents comparison with $\mathrm{Pb}$ group. ${ }^{*} p<0.05,{ }^{* \star} p<0.01,{ }^{\star * *} p<$ $0.001, \# p<0.05$, \#\#p $<0.01$, \#\#\#p $<$ 0.001 based on one way ANOVA. 

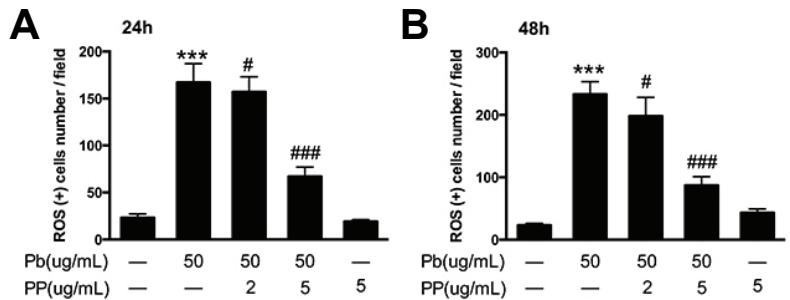

Fig. 6. Polyphenols scavenged ROS production induced by $\mathrm{Pb}$. (A) ROS positive cells per field at $24 \mathrm{~h}$. (B) ROS positive cells per field at $48 \mathrm{~h}$. Data in the figures represent average $\pm S D$. $(n=3)$ * represents comparison with control group and \# represents comparison with $\mathrm{Pb}$ group. ${ }^{*} p<0.05,{ }^{\star \star} p<0.01,{ }^{\star \star *} p<0.001, \# p<0.05, \# \# p<$ 0.01 , \#\#\#p<0.001 based on one way ANOVA.

blot analysis on several important ROS mediated signaling pathway proteins was performed. The expression levels of JNK and p-JNK were measured in primary mesangial cells. Phosphorylation of JNK was shown increased when $\mathrm{Pb}$ was treated (Fig. 7A). The results showed that polyphenols partially reversed the phosphorylation of JNK (Fig. 7C).

\section{DISCUSSION}

Lead is a heavy metal widely spread in the environment as one of the most common natural and anthropogenic contaminants. Lead has been used intensively in human history including construction, food additive, decoration, and even cosmetics. $\mathrm{Pb}$ can be absorbed through the gastrointestinal tract from water and food poisoned by lead in the soil and also through the respiratory tract by inhalation of $\mathrm{Pb}$ contained dust. After absorbed to human body, $\mathrm{Pb}$ accumulates in different types of tissue according to different tissue-specific intimacy (Chandran and Cataldo, 2010). The half-life of $\mathrm{Pb}$ in circulation blood is about 5 weeks and 2 years in the central nervous system. $\mathrm{Pb}$ can be permanently deposited in the bone. Symptoms of $\mathrm{Pb}$ intoxication are quite vague but commonly seen in daily lives. The symptoms can be found in digestive system such as vomiting, abdominal pain, nausea, and constipation. In nervous system, the neurotoxicity of $\mathrm{Pb}$ can result in cognitive disorders, memory alterations and onset of psychiatric disturbances (Mason et al., 2014). As for cardiovascular system, lead exposure has been reported associated with blood pressure levels, stroke, peripheral vascular diseases and coronary heart disease (Shinkai and Kaji, 2012). The endocrine system is also heavily affected by lead intoxication on hypothalamic-pituitary axis and thyroid hormone kinetics (Doumouchtsis et al., 2009). It is reported that an estimated 310,000 children below five-year-old have elevated blood $\mathrm{Pb}$ levels (Warniment et al., 2010). The situation of Chinese children is much worse because of the severe pollution of food, water and air (van der Kuijp et al., 2013; Ye and Wong, 2006).

The mechanism of $\mathrm{Pb}$ induced intoxication is still not fully understood. We noticed that $\mathrm{Pb}$ toxicity have particular enzyme targets like heme synthesis enzymes and antioxidant enzymes such as catalase, superoxide dismutase, and peroxidase (Nemsadze et al., 2009). The inhibition of antioxidant enzymes cause over generation of ROS, thus induce oxidative stress. Although the primary target organ of lead toxicity is the central nervous system, oxidative stress caused by $\mathrm{Pb}$ exposure also induces poisoning in other systems (Garza et al., 2006; Nemsadze et al., 2009). ROS mediated oxidative stress plays an important role in $\mathrm{Pb}$ induced renal dysfunction. In our study, we showed that $\mathrm{Pb}$ significantly increased ROS generation in the primary kidney mesangial cells. Over-generation of ROS resulted in increased cell apoptosis and expression of inflammatory cytokines including TNF- $\alpha, \mathrm{IL}-1-\beta$ and IL- 6 . The effects of the these inflammatory cytokines were regarded crucial in renal toxicity induced by $\mathrm{Pb}$ in vivo. It is also interesting to notice that the anti-apoptotic gene $\mathrm{Bcl}-2$ were upregulated by $\mathrm{Pb}$ and suppressed by PP just like the pro-apoptotic gene Bax. We currently could not explain this phenomenon and further in detail molecular mechanism should be explored. Several recent reports focused on the epigenetic regulations of $\mathrm{Pb}$ exposure induced pathogenesis (Li et al., 2011; Luo et al., 2014). They found that chronic $\mathrm{Pb}$ exposure could lead to histone acetylation level increase suggesting the involvement of epigenetic histone acetylation in $\mathrm{Pb}$ toxicity pathologies.

Intensive studies have been made on the potential beneficial effects of polyphenols in human health. Polyphenols almost have protective effects in multiple organs and systems in human body. Studies have shown that polyphenols are protective
A
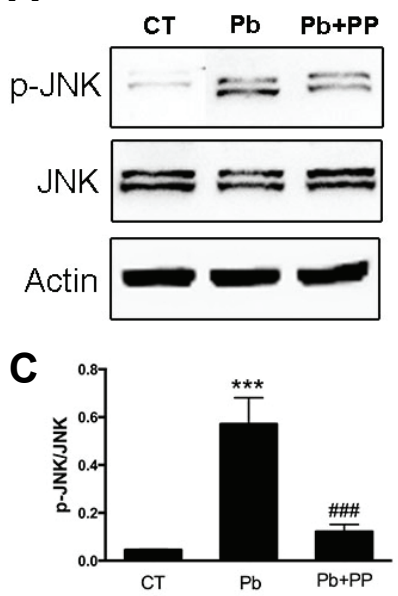

B
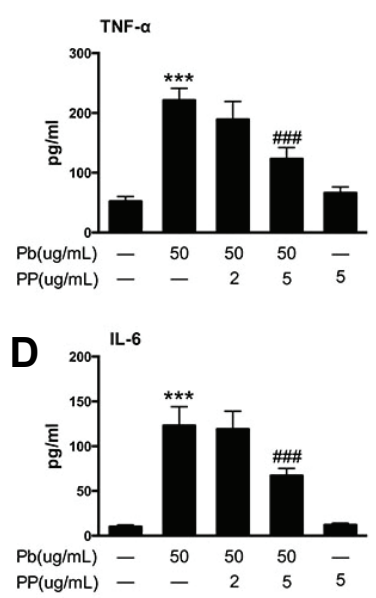

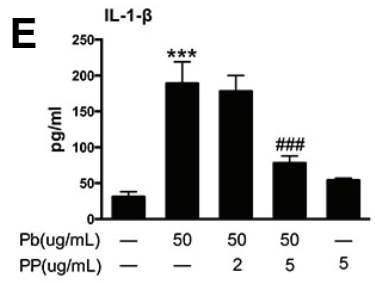

Fig. 7. Polyphenols suppressed inflammatory cytokines release through JNK-MAPK pathway. (A) Representative WB images of JNK, p-JNK. (B) ELISA assay of TNF- $\alpha$. (C) Quantification of $p-$ JNK/JNK ratio. (D) ELISA assay of IL-6. (E) ELISA assay of IL-1- $\beta$. Data in the figures represent average $\pm S D$. $(n=5)$ * represents comparison with control group and \# represents comparison with $\mathrm{Pb}$ group. ${ }^{*} p<0.05,{ }^{* *} p<0.01,{ }^{* * *} p<$ $0.001, \# p<0.05, \# \# p<0.01, \# \# \# p$ $<0.001$ based on one way ANOVA. 
on renal function with ischemia/reperfusion injury ( $\mathrm{Li}$ et al., 2014), heavy metal intoxication (Kusumoto et al., 2011), and diabetic nephropathy (Yang et al., 2013). In our study, for the first time, we revealed that polyphenols can also protect renal toxicity resulted from $\mathrm{Pb}$ exposure. Another issue worthy to be noticed is the toxicity of polyphenols themselves due to the excess intake. Polyphenols side effects in kidney occured when they were over intaken according to Akira Murakami et al (Murakami, 2014). Although the side effects of polyphenols were not shown in our study, it is still important to be aware of the property of polyphenols as foreign molecules and the possibility of activating self-defense systems both at cellular level or general level of immune system.

In conclusion, we presented the protective effects of polyphenols on $\mathrm{Pb}$-induced renal dysfunction. We proved that polyphenols could efficiently scavenge ROS generation caused by $\mathrm{Pb}$ exposure, thus attenuated ROS-mediated inflammatory cytokines secretion through ERK/JNK/p38 pathways. Polyphenols showed its potency in treating and preventing $\mathrm{Pb}$ exposure induced renal poisoning as a beneficial food supplementary.

\section{REFERENCES}

Bohn, T. (2014). Dietary factors affecting polyphenol bioavailability. Nutr. Rev. 72, 429-452.

Cardona, F., Andres-Lacueva, C., Tulipani, S., Tinahones, F.J., and Queipo-Ortuno, M.I. (2013). Benefits of polyphenols on gut microbiota and implications in human health. J. Nutr. Biochem. 24, 1415-1422.

Chandran, L., and Cataldo, R. (2010). Lead poisoning: basics and new developments. P Pediatr Rev. 31, 399-405; quiz 406.

Chu, A.J. (2014). Antagonism by bioactive polyphenols against inflammation: a systematic view. Inflamm. Allergy Drug Targets 13 , 34-64.

Copello, G.J., Pesenti, M.P., Raineri, M., Mebert, A.M., Piehl, L.L., de Celis, E.R., and Diaz, L.E. (2013). Polyphenol-SiO2 hybrid biosorbent for heavy metal removal. Yerba mate waste (llex paraguariensis) as polyphenol source: kinetics and isotherm studies. Colloids Surf. B. Biointerfaces 102, 218-226.

Dai, W., Du, H., Fu, L., Jin, C., Xu, Z., and Liu, H. (2009). Effects of dietary $\mathrm{Pb}$ on accumulation, histopathology, and digestive enzyme activities in the digestive system of tilapia (Oreochromis niloticus). Biol. Trace Elem. Res. 127, 124-131.

Doumouchtsis, K.K., Doumouchtsis, S.K., Doumouchtsis, E.K., and Perrea, D.N. (2009). The effect of lead intoxication on endocrine functions. J. Endocrinol. Invest. 32, 175-183.

Garza, A., Vega, R., and Soto, E. (2006). Cellular mechanisms of lead neurotoxicity. Med. Sci. Monit. 12, RA57-65.

Joven, J., Micol, V., Segura-Carretero, A., Alonso-Villaverde, C., Menendez, J.A., and Bioactive Food Components, P. (2014). Polyphenols and the modulation of gene expression pathways: can we eat our way out of the danger of chronic disease? Crit. Rev. Food Sci. Nutr. 54, 985-1001.

Khurana, S., Venkataraman, K., Hollingsworth, A., Piche, M., and Tai, T.C. (2013). Polyphenols: benefits to the cardiovascular system in health and in aging. Nutrients 5, 3779-3827.

Kusumoto, M., Kamobayashi, H., Sato, D., Komori, M., Yoshimura, M., Hamada, A., Kohda, Y., Tomita, K., and Saito, H. (2011). Alleviation of cisplatin-induced acute kidney injury using phytochemical polyphenols is accompanied by reduced accumulation of indoxyl sulfate in rats. Clin. Exp. Nephrol. 15, 820830.

Li, C., Xu, M., Wang, S., Yang, X., Zhou, S., Zhang, J., Liu, Q., and Sun, Y. (2011). Lead exposure suppressed ALAD transcription by increasing methylation level of the promoter CpG islands. Toxicol. Lett. 203, 48-53.

Li, Y.W., Zhang, Y., Zhang, L., Li, X., Yu, J.B., Zhang, H.T., Tan, B.B., Jiang, L.H., Wang, Y.X., Liang, Y., et al. (2014). Protective effect of tea polyphenols on renal ischemia/reperfusion injury via suppressing the activation of TLR4/NF-kappaB p65 signal pathway Gene 542, 46-51.

Liu, M.Y., Hsieh, W.C., and Yang, B.C. (2000). In vitro aberrant gene expression as the indicator of lead-induced neurotoxicity in U373MG cells. Toxicology 147, 59-64.

Liu, C.M., Sun, Y.Z., Sun, J.M., Ma, J.Q., and Cheng, C. (2012). Protective role of quercetin against lead-induced inflammatory response in rat kidney through the ROS-mediated MAPKs and NFkappaB pathway. Biochim. Biophys. Acta 1820, 1693-1703.

Luo, W., Ruan, D., Yan, C., Yin, S., and Chen, J. (2012). Effects of chronic lead exposure on functions of nervous system in Chinese children and developmental rats. Neurotoxicology 33, 862-871.

Luo, M., Xu, Y., Cai, R., Tang, Y., Ge, M.M., Liu, Z.H., Xu, L., Hu, F., Ruan, D.Y., and Wang, H.L. (2014). Epigenetic histone modification regulates developmental lead exposure induced hyperactivity in rats. Toxicol. Lett. 225, 78-85.

Mandal, S., Mukherjee, S., Chowdhury, K.D., Sarkar, A., Basu, K., Paul, S., Karmakar, D., Chatterjee, M., Biswas, T., Sadhukhan, G.C., et al. (2012). S-allyl cysteine in combination with clotrimazole downregulates Fas induced apoptotic events in erythrocytes of mice exposed to lead. Biochim. Biophys. Acta 1820, 9-23.

Mason, L.H., Harp, J.P., and Han, D.Y. (2014). Pb neurotoxicity: neuropsychological effects of lead toxicity. BioMed Res. Int. 2014, 840547.

Mishra, K.P., Singh, V.K., Rani, R., Yadav, V.S., Chandran, V., Srivastava, S.P., and Seth, P.K. (2003). Effect of lead exposure on the immune response of some occupationally exposed individuals. Toxicology 188, 251-259.

Murakami, A. (2014). Dose-dependent functionality and toxicity of green tea polyphenols in experimental rodents. Arch. Biochem. Biophys. 557, 3-10.

Navarro-Moreno, L.G., Quintanar-Escorza, M.A., Gonzalez, S., Mondragon, R., Cerbon-Solorzano, J., Valdes, J., and CalderonSalinas, J.V. (2009). Effects of lead intoxication on intercellular junctions and biochemical alterations of the renal proximal tubule cells. Toxicol. In Vitro 23, 1298-1304.

Nemsadze, K., Sanikidze, T., Ratiani, L., Gabunia, L., and Sharashenidze, T. (2009). Mechanisms of lead-induced poisoning. Georgian Med. News 92-96.

Ohara, M., and Ohyama, Y. (2014). Delivery and application of dietary polyphenols to target organs, tissues and intracellular organelles. Curr. Drug Metabol. 15, 37-47.

Poreba, R., Gac, P., Poreba, M., and Andrzejak, R. (2012). Assessment of cardiovascular risk in workers occupationally exposed to lead without clinical presentation of cardiac involvement Envir. Toxicol. Pharmacol. 34, 351-357.

Qiao, J., Kong, X., Kong, A., and Han, M. (2014). Pharmacokinetics and biotransformation of tea polyphenols. Curr. Drug Metabol. 15, 30-36.

Shinkai, Y., and Kaji, T. (2012). Cellular defense mechanisms against lead toxicity in the vascular system. Biol. Pharm. Bull. 35, 18851891.

Struzynska, L., Dabrowska-Bouta, B., Koza, K., and Sulkowski, G. (2007). Inflammation-like glial response in lead-exposed immature rat brain. Toxicol. Sci. 95, 156-162.

van der Kuijp, T.J., Huang, L., and Cherry, C.R. (2013). Health hazards of China's lead-acid battery industry: a review of its market drivers, production processes, and health impacts. Environ. Health 12,61 .

Warniment, C., Tsang, K., and Galazka, S.S. (2010). Lead poisoning in children. Am. Fam. Physician 81, 751-757.

Yang, Y.S., Wang, C.J., Huang, C.N., Chen, M.L., Chen, M.J., and Peng, C.H. (2013). Polyphenols of Hibiscus sabdariffa improved diabetic nephropathy via attenuating renal epithelial mesenchymal transition. J. Agric. Food Chem. 61, 7545-7551.

Yang, P., He, X., and Malhotra, A. (2014). Epigenetic targets of polyphenols in cancer. J Environ Pathol Toxicol Oncol. 33, 159-165

Ye, X., and Wong, O. (2006). Lead exposure, lead poisoning, and lead regulatory standards in China, 1990-2005. Regul. Toxicol. Pharmacol. 46, 157-162.

Zou, D., and Xie, A. (2013). Influence of polyphenol-plasma protein interaction on the antioxidant properties of polyphenols. Curr. Drug Metabol. 14, 451-455. 